\title{
DIGITALCOMMONS
}

@WAYNESTATE -

Wayne State University

9-1-2015

\section{Combating Racial Health Disparities through Medical Education: The Need for Anthropological and Genetic Perspectives in Medical Training}

Deborah A. Bolnick

Department of Anthropology and Population Research Center, University of Texas at Austin, Austin, TX, deborah.bolnick@austin.utexas.edu

\section{Recommended Citation}

Bolnick, Deborah A., "Combating Racial Health Disparities through Medical Education: The Need for Anthropological and Genetic Perspectives in Medical Training" (2015). Human Biology Open Access Pre-Prints. 107.

http://digitalcommons.wayne.edu/humbiol_preprints/107 
Combating Racial Health Disparities Through Medical Education: The Need for Anthropological and Genetic Perspectives in Medical Training

\title{
Deborah A. Bolnick ${ }^{1}$
}

${ }^{1}$ Department of Anthropology and Population Research Center University of Texas at Austin, deborah.bolnick@austin.utexas.edu, Department of Anthropology University of Texas at Austin 2201 Speedway Stop C3200 Austin, TX 78712

Keywords: Race, Health Disparities, Human Genetic Variation, Evolutionary Medicine, Medical School Curriculum

Issue: 87.4

\begin{abstract}
Despite major public health initiatives, significant disparities persist between racially- and ethnically-defined groups in the prevalence of disease, access to medical care, quality of medical care, and health outcomes for common causes of morbidity and mortality in the United States. It is critical that we develop new and creative strategies to address such inequities, mitigate the social, environmental, institutional, and genetic determinants of poor health, and combat the persistence of racial profiling in clinical contexts that further exacerbates racial/ethnic health disparities. In this article, I argue that medical education is a prime target for intervention, and that there is an important role for anthropologists and human population geneticists to play in efforts to reform medical curricula in this country. Medical education would benefit greatly from the incorporation of anthropological and genetic perspectives on the complexities of race, human genetic variation, epigenetics, and the causes of racial/ethnic disparities. Medical students and practicing physicians should also receive training on how to use this knowledge to improve clinical practice, diagnosis, and treatment for racially diverse populations.
\end{abstract}

For the last two decades, one of the primary goals of the U.S. Department of Health and Human Services (HHS), the National Institutes of Health (NIH), the Institute of Medicine (IOM), the Centers for Disease Control and Prevention (CDC), and many public health programs has been the reduction of health disparities in the United States (Smedley et al. 2003; Centers for Population Health and Health Disparities 2007; CDC 2011; HealthyPeople.gov). However, significant disparities have persisted, not only in the prevalence of disease, access to medical care, and quality of care, but also in health outcomes for the most common causes of morbidity and mortality (including cardiovascular and lung disease, infectious disease, cancer, and diabetes). These disparities fall largely along racial, ethnic, 
and class lines, with poor, uninsured, and minority populations affected most negatively (Table 1; Shields et al. 2005; Betancourt 2006; CDC 2011). In some geographic areas, local disparities are even greater than what the national statistics show, and, in many cases, inequalities have increased, rather than decreased, in recent years. Where I live in Central Texas, for example, black infant mortality is now almost four times greater than white infant mortality (Tang 2012), in contrast to the two-fold difference in black and white infant mortality rates nationally (Table 1). Ongoing demographic shifts are expected to further exacerbate this and other disparities, both in Central Texas and nationwide.

Given these trends, it is critical that we develop and implement new and creative strategies to address such inequities. There is an urgent need for novel approaches to mitigate (a) the social, environmental, institutional, and genetic determinants of poor health, and (b) the persistence of racial profiling in clinical contexts, which further contributes to racial/ethnic disparities. While achieving significant reductions in health disparities in the United States will require a sustained, wide-ranging, and multifaceted effort, one component of this effort that is gaining steam now is focused on medical education. HHS, NIH, the IOM, and others have all called for changes in medical training to help reduce health inequities and to improve clinical practice, diagnosis, and treatment for diverse patient populations (Smedley et al. 2003; Betancourt 2006; Centers for Population Health and Health Disparities 2007; Smith et al. 2007; HHS 2011; Awosogba et al. 2013; Green 2015; Williams and Wyatt 2015). These calls have not been explicitly aimed at anthropologists or human population geneticists, but there is an important role for members of these disciplines to play in efforts to reform medical training in this country. In particular, medical education would benefit from greater integration of anthropological and genetic perspectives on the complexities of race, human genetic and epigenetic variation, and the causes of racial/ethnic health disparities.

\section{Current Shortcomings in Medical Education and Clinical Practice}

Recent surveys of physicians and medical curricula have made it clear that there is a significant disconnect between the training provided in medical school and what physicians need to know about race, human genetic and epigenetic variation, and the causes of racial health disparities (Bonham et al. 2014; Brooks 2015; Green 2015). For example, most physicians see knowledge of genetics and human genetic variation as increasingly important in clinical contexts, but only $5.1 \%$ rate their knowledge of these subjects as "very good" or "excellent" (Bonham et al. 2014). Given this, it is perhaps not surprising that many doctors mistakenly believe that human genomic variation maps neatly onto American racial categories (Braun et al. 
2007; Baer et al. 2013; Hunt et al. 2013; Tuckson et al. 2013). This misconception demonstrates that many physicians have not been adequately exposed to the extensive body of research showing that U.S. racial categories reflect sociopolitical factors and American historical experience more than biology (Ossorio and Duster 2005; Braun et al. 2007; Baer et al. 2013; Barbujani et al. 2013). Similarly, many physicians believe that genetic differences between racial groups account for the racial health disparities we see today (Braun et al. 2007; Baer et al. 2013; Hunt et al. 2013; Tuckson et al. 2013; Bonham et al. 2014; Kaufman et al. 2015), not realizing that there is sizeable body of scientific literature showing that most health disparities are caused by social and environmental factors (Sankar et al. 2004; Gravlee 2009; Braveman et al. 2011; Thayer and Kuzawa 2011; Sullivan 2013; Kaufman et al. 2015). Clinicians do identify social and environmental factors as other important determinants of their patients' morbidity and mortality, but they feel ill-equipped to help their patients address and overcome the social, structural, and environmental conditions that have a negative impact on their health (Goldstein and Holmes 2011; Robert Wood Johnson Foundation 2011). Thus, these findings indicate that there are significant gaps and shortcomings in the training most physicians receive in medical school.

It is in recognition of these shortcomings that HHS, NIH, the IOM, and others have called for changes in medical training and clinical practice to help reduce racial and ethnic health inequities (Shields et al. 2005; Betancourt 2006; Centers for Population Health and Health Disparities 2007; Smith et al. 2007; HHS 2011; Awosogba et al. 2013; Brooks 2015; Green 2015). The Accreditation Council for Graduate Medical Education's clinical competencies guiding medical school pedagogy also stress the need for medical schools to address the social and cultural aspects of patient care, as well as the genetic, environmental, and institutional influences on health (Joyce 2006; abp.org). Likewise, the Joint Commission for Accreditation of Healthcare Organizations advocates knowledge of the various determinants of health and sociocultural factors affecting patient care as part of their recommendations to help hospitals improve the quality of care, comply with Joint Commission requirements, and increase health equity (The Joint Commission 2010; jointcommission.org/topics/health_equity.aspx).

However, despite widespread recognition that clinical competence requires a working knowledge of the social, institutional, and genetic determinants of health, many medical schools and healthcare agencies lack the expertise among their faculty and staff to provide sufficient training in these subjects. A number of programs have been established around the country to help fill these gaps (such as the Program on Ethnicity, Culture, and Health Outcomes at the University of North Carolina, the Program in Medical Education for the Latino Community at the University of California-Irvine, the Minority Health and Health Disparities Education and Research Program at the University of Maryland, the Center for 
Medicine, Health, and Society at Vanderbilt University, and the medical elective course on Race, Health, and Structural Inequality at Brown University's Alpert Medical School), but more such programs are needed. Furthermore, many of the existing programs have had a more limited impact that we might have hoped, perhaps because of who they teach and how they interface with the core medical school curriculum. Some teach only or primarily pre-medical students, and their lessons may be forgotten if not reinforced during medical school. Many others reach only a subset of medical students because the material is largely relegated to supplementary courses, optional electives, or secondary degrees, rather than being fully integrated into the core curriculum. Consequently, many medical students and physicians have never been taught to think carefully and critically about the complexities of race, genetics, and health disparities, and they harbor misconceptions (such as those noted above) as a result.

These misconceptions can lead to scientifically invalid and discriminatory racial profiling in clinical contexts, and such practices are known to result in improper treatment decisions, medical errors, and a failure to recognize important but non-genetic causes of poor health in minority patients (Garcia 2003; Smedley et al. 2003; Hoberman 2012; Fofana 2013). For example, folk beliefs about African-Americans and other minorities being less sensitive to pain have persisted since times of slavery, and this belief has been tied to inequities in how pain medication is dispensed in hospital emergency rooms (Hoberman 2012; Hoffman et al. 2016). Todd et al. (1993, 2000) found that 55\% of Hispanics and $43 \%$ of blacks received no pain medication when admitted with long-bone fractures, compared to $26 \%$ of whites. This disparity persisted despite similar pain reports and after adjusting for confounders (Todd et al. 1993, 2000). Similarly, Johnson et al. (2013) found that black and Hispanic children admitted to the emergency room with severe abdominal pain are significantly less likely to receive any analgesic than white children, and they experience a slower recovery and more prolonged hospital stay as a result. Practices like this must be eliminated if we wish to reduce racial/ethnic health disparities in this country.

Some other well-documented examples of racial/ethnic profiling and unequal treatment in the clinic are given in Table 2 . The last is perhaps especially noteworthy because it involves sickle-cell anemia, a condition that has been widely studied by biological anthropologists and population geneticists. Because of the common misconception that sickle-cell anemia is a "black" disease, there have been a number of well-documented misdiagnoses in the clinic, stemming from the fact that some physicians have not known that the sickle-cell allele is common in the Mediterranean basin but not some parts of Africa (Witzig 1996). The nonconcordance between race and sickle-cell anemia is commonly taught in undergraduate and graduate courses in biological anthropology and human population genetics, but it is not always covered in medical school courses. Thus, 
there is clearly a role for anthropologists and human geneticists to play in improving what is taught at medical schools regarding race, human genetic variation, and the causes of racial health disparities.

\section{RECOMMENDATIONS FOR MEDICAL EDUCATION}

Because traditional approaches to medical training on race/ethnicity, human genetic variation, health disparities, and cultural competency ${ }^{1}$ have well-documented shortcomings (Betancourt 2006; Braun et al. 2007; Metzl and Hansen 2014; Metzl and Roberts 2014), it is critical that we develop more effective medical education and improved clinical practices to reduce health disparities and achieve better health outcomes for diverse patient populations. In particular, there is a real need for medical educators to work closely with anthropologists, sociologists, human population geneticists, and historians of race to write relevant learning objectives and to design innovative, evidence-based, and anthropologically informed training modules that could be integrated into medical curricula as a way to fill the gaps that have been previously identified. These modules could include clinical case studies, short online learning exercises, lecture material, readings, and/or discussion guides, all of which could be easily incorporated into existing medical school curricula. This approach would allow new training to be woven seamlessly throughout the core preclinical and clinical curriculum, so that all medical students receive explicit training on the complexities of race/ethnicity, human genomic variation, epigenetics, and both the genetic and non-genetic causes of poor health and health disparities. It would also be beneficial for anthropologists, human population geneticists, sociologists, and historians to help teach these modules. This approach would help medical students see the benefits of a multifaceted approach to medicine.

For example, as new molecular technologies have emerged and become increasingly accessible over the last decade, it has become important for medical students to learn how to collect and use genomic information in a variety of clinical and research settings, including when making diagnosis and treatment decisions. Physicians must also be able to contextualize the genomic data, though, integrating it with information about a patient's social and physical environment, life history, and ancestry. This contextualization is necessary because recent research in epigenetics (Johnstone and Baylin 2010; Thayer and Kuzawa 2011; Tammen et al.

\footnotetext{
${ }^{1}$ Cultural competency training has traditionally focused on patient beliefs and behaviors, doctorpatient communication, and culture as a static causal variable in individual health outcomes. While initially a breakthrough in medical training, it is now widely seen as ineffective and insufficient, in part because it neglects the social, institutional, and structural causes of population differences in health (Braun et al. 2007; Carpenter-Song et al. 2007; Kumagai and Lypson 2009; Metzl and Hansen 2014).
} 
2013; Thayer and Non 2015), neuroplasticity (McClung and Nestler 2008; Frodi et al. 2010), and epidemiology (Yusuf and Anand 2010; Kaufman et al. 2015) has shown that both social and physical environments influence gene expression, biological development, and individual health outcomes. Understanding the interplay between socioeconomic, environmental, genetic, and epigenetic factors is therefore crucial if physicians are to develop effective prevention and treatment plans for many medical conditions. Treating cardiovascular disease and obesity, for instance, now requires familiarity with epidemiological models that emphasize the role of factors like stress, nutrition, and exercise in disease progression (Yusuf and Anand 2010; Malik et al. 2013; Kaufman et al. 2015). Furthermore, to reduce disparities in the prevalence and outcomes of these diseases, physicians need to build collaborations with community partners, health policy makers, and other public health experts in order to address the social, institutional, and structural dimensions of health disparities.

While many different approaches could be taken to implement more effective medical training on these subjects, I outline here a set of recommendations developed in 2013 and 2014 by a series of working groups held at the University of Texas at Austin. These working groups involved a multidisciplinary group of anthropologists, biologists, historians, physicians, and others, and they brought together members of the university community, local health care practitioners, representatives of city and state agencies, and scientists, social scientists, and administrators from other U.S. and Canadian medical schools, universities, and the NIH. The recommendations that emerged provide examples of how expertise from anthropology, human population genetics, and evolutionary biology can inform and improve the learning objectives and curriculum at medical schools.

Broadly, these working groups recommended that medical schools implement innovative, evidence-based medical training that incorporates (1) recent advances in genomics, epigenetics, and the quantitative methods needed to interpret such data, (2) emerging understandings of the environmental, social, economic, and structural influences on human biology and health, especially those that shape poor health in racial/ethnic minorities and disadvantaged groups, and (3) opportunities for medical students and residents to help design and implement interventions aimed at improving population health and reducing health disparities. More specifically, they made five recommendations:

Recommendation \#1: Medical students should learn the complexities of race, ethnicity, and human genomic variation, and they should understand when and how race, ethnicity, and genetic ancestry should be used in clinical contexts. Medical students should learn to assess a patient's genotype and genetic ancestry empirically, using genetic tests, rather than using skin color, race, or ethnicity as a proxy. 
This recommendation reflects the fact that it is critical that physicians base diagnosis and treatment decisions for each patient on the presence or absence of clinically relevant factors for that individual, regardless of the patient's sociallyascribed race or ethnicity. Racial and ethnic profiling in clinical contexts results in improper treatment and medical errors, contributing to racial/ethnic disparities in health. It is also important that doctors understand that genetic factors are not responsible for most racial/ethnic disparities so that they assess other factors that may contribute to poor health in minority patients.

Recommendation \#2: Social medicine and social epidemiology should be incorporated into preclinical and clinical training. Medical students should understand the sociocultural, economic, environmental, and structural factors that shape poor health in disadvantaged groups and racial/ethnic minorities, and they should be able to apply the principles of evidence-based medicine in clinical practice, with diagnosis and treatment decisions based on scientific evidence rather than racial/ethnic stereotypes.

In social medicine, social science and humanities perspectives inform the study of health patterns and contribute to the design and implementation of effective health interventions at the individual and community level. Social epidemiology is a branch of epidemiology that focuses on the role of social and environmental factors in the distribution of disease, and it supports appropriate diagnosis and treatment of disease. These approaches to medicine reflect evidence that the vast majority of population health outcomes are attributable to socioeconomic factors, environmental influences, and health behaviors (Robert Wood Johnson Foundation 2011). Furthermore, the risks for developing coronary heart disease, stroke, lung cancer, chronic obstructive pulmonary disease (COPD), infections, and mental disorders (the major causes of mortality and morbidity in the world), as well as prognoses and treatment outcomes for those who develop these diseases and disorders, are strongly predicted by social factors like socioeconomic status and place of residence (Braveman et al. 2011; CDC 2011). It is therefore critical that $21^{\text {st }}$ century physicians learn to understand and address the socioeconomic and environmental determinants of poor health, especially those that disproportionately affect racial/ethnic minorities and disadvantaged groups. Medical school faculty and students also need to be aware of the racial profiling that occurs in clinical contexts and commonly distorts diagnoses and treatments of black and Hispanic patients across a range of medical subdisciplines.

Recommendation \#3: Medical schools should provide training in structural competency as well as more effective, evidence-based cultural competency training.

Cultural competency training has traditionally focused on patient beliefs and behaviors, doctor-patient communication, and culture as a static causal variable 
in individual health outcomes. While initially a breakthrough in medical training, it is now widely seen as ineffective and insufficient, in part because it neglects the social, institutional, and structural causes of population differences in health (Braun et al. 2007; Carpenter-Song et al. 2007; Kumagai and Lypson 2009; Metzl and Hansen 2014; Metzl and Roberts 2014). Structural competency shifts the focus from individuals to institutions, communities, and policies that shape clinical interactions and health outcomes (Metzl and Hansen 2014; Metzl and Roberts 2014). Medical school faculty and students should learn to identify the key social and structural determinants of health that should be targeted for intervention, and they should learn to design and implement structural interventions in clinical, community, and public policy contexts. Medical schools should also provide cultural competency training using the newest and most effective evidence-based models of cultural competency (Carpenter-Song et al. 2007; Kumagai and Lypson 2009; Coria et al. 2013; Metzl and Hansen 2014; Metzl and Roberts 2014).

Recommendation \#4: Key aspects of evolutionary theory and human evolutionary biology should be incorporated into the medical curriculum, focusing on how knowledge of evolution improves a physician's ability to prevent, diagnose, and treat disease.

While evolutionary theory and human evolutionary biology have long been viewed as disconnected from the day-to-day practice of medicine, it has become increasingly clear in recent years that evolutionary biology has many practical applications in medicine and public health (Nesse and Schiffman 2003; Trevathan et al. 2008; Gluckman et al. 2009; Williams 2009; Nesse et al. 2010; Omenn 2010; Pearlman 2013; Alcock and Schwartz 2011; Gluckman and Bergstrom 2011; Stearns 2011, 2012). For example, understanding human evolutionary history and the resulting patterns of human genetic diversity within and across populations can improve diagnosis, treatment, and preventative care (Bolnick et al., in review). Physicians should also learn to apply analytical tools from evolutionary biology (ex. phylogenetic and population genetic analyses) to identify pathogens, trace sources of infection, determine patient ancestry, and identify genetic markers of disease risk. DNA sequencing and phylogenetic analysis of the Ebola virus in infected patients during the 2014 epidemic in West Africa, for instance, made it possible to pinpoint the source of the outbreak and track patterns of viral transmission, allowing health workers to identify the interventions needed to slow the spread of the virus (Gire et al. 2014). Other examples, as well as a more thorough discussion of how human evolutionary biology, phylogenetics, and population genetic analyses can be integrated into medical education and applied to improve medical diagnosis, treatment, and preventative care, are presented in Bolnick et al. (in review), along with more specific learning objectives linked to established competencies in medical education. 
Recommendation \#5: Medical students, residents, and faculty should work with public health experts to design and implement interventions that will improve population health, reduce health disparities, and help solve the challenging health problems that exist both locally and nationally in the United States.

Medical schools should build partnerships with local healthcare providers, community members and organizations, local and state healthcare agencies, health policy makers, and other public health experts so students, residents, and faculty have the opportunity to help develop and undertake concrete steps to address the social, institutional, and structural causes of poor health and health disparities, both at the local and national level.

Examples of specific learning objectives associated with these recommendations are provided in Table 3.

\section{IMPLEMENTATION AND APPLICATIONS}

Providing medical training in these areas would address critical needs and prepare medical students to meet the challenges and opportunities of $21^{\text {st }}$ century medicine. By teaching students to understand the genetic, sociocultural, environmental, and structural determinants of health, and by training them to undertake interventions to improve health in clinical, institutional, community, and policy contexts, we may begin to gain some traction in the fight to reduce racial/ethnic health disparities one of the most persistent problems in medicine today.

As noted earlier, much of the training recommended here could be provided through short modules inserted into existing lectures, online learning exercises, consideration of relevant clinical case studies, student readings, and discussions integrated into the preclinical curriculum, with subsequent clinical training building on what is taught in preclinical courses. For example, when covering molecular biology and genetics, a clinical case study about a diagnosis of sickle-cell anemia could provide the framework for teaching medical students about (a) the molecular genetics of single gene disorders, (b) the distribution of this particular disorder and the evolutionary and historical reasons for why it is found in sub-Saharan Africa, the Middle East, India, southern Europe, and certain areas of the Americas (recommendation \#4), (c) misconceptions about sickle-cell as a black disease and the disconnect between human genetic variation and race (recommendation $\# 1)$, (d) the clinical and social consequences of such misconceptions (recommendations \#1 and \#2), and (e) the quantitative techniques necessary to make rational diagnosis and treatment decisions for individuals (recommendations \#1 and \#2). 
Another case study, about the diagnosis, treatment, and management of type II diabetes, could be covered when studying the endocrine system. This case study could show how genetic, epigenetic, social, environmental, and structural factors all shape the course of disease (recommendations \#1-\#4): genetic variants at the SLC16A11 locus are associated with an increased risk of type II diabetes and an earlier age of onset in Mexican and Latin American populations (The SIGMA Type 2 Diabetes Consortium 2014), for example, but socioeconomic conditions, diet, lifestyle, and healthcare availability are also important, as diabetes has only become prevalent in Native Americans in the last 75 years (Hill 1997). Discussions of the complexities of type II diabetes would provide students with concrete, practical advice for dealing with challenging clinical situations, and this case could help students learn to consider health interventions at the individual, population, and policy levels (recommendations \#3 and \#5).

Similarly, a third case study, focused on hypertension and cardiovascular disease, could draw attention to the fact that African-Americans exhibit a higher rate of hypertension than white Americans, but populations in West Africa exhibit a lower rate of hypertension than both (Cooper et al. 2005) - indicating that socioeconomic, environmental, and/or structural factors in the U.S. are more important than genetic ancestry in producing this disparity (recommendations \#1\#3). While considering this case study, students could meet with local healthcare providers, representatives of community organizations and healthcare agencies, health policy makers, or other public health experts to discuss interventions that could be implemented to help alleviate this disparity (recommendations \#3 and \#5). Other case studies and associated lesson plans could be incorporated throughout preclinical and clinical training, allowing the recommendations made here to be implemented in a way that is compatible with existing curriculum plans.

In addition to providing medical training on these subjects as part of the medical school curriculum, continuing medical education (CME) events can be held to help educate current health practitioners and medical educators. In September 2013, for example, we held a one-day CME conference at the University of Texas at Austin on "Addressing Racial/Ethnic Health Disparities: Best Practices for Clinical Care and Medical Education in the $21^{\text {st }}$ Century". Speakers from around the country gave presentations about (a) the pattern of human genomic variation and its relationship to socially-ascribed racial/ethnic categories and disease, (b) evidence-based medicine and the social, environmental, and structural determinants of health, (c) common misconceptions and clinical best practices for improving care and reducing health disparities, and (d) and best practices for medical education in the $21^{\text {st }}$ century. Each session had explicit learning objectives, and the healthcare professionals in attendance earned CME credits for the day, including credits for education in medical ethics and professional responsibility. Feedback from attendees after the conference showed that the material was new for 
many, and virtually all said that they would incorporate lessons from the day into their clinical practices. Many also expressed keen interest in learning more about the topics discussed at the conference. This feedback suggests that many practicing physicians and other medical professionals would be interested in attending CME events focused on these issues.

\section{CONCLUSIONS}

There is an important role for anthropologists and human population geneticists to play in training medical students and physicians to better understand the complexities of race and ethnicity, human genomic variation, and both the genetic and non-genetic causes of poor health and health disparities. The learning objectives and training activities proposed here provide examples of how expertise from anthropology, human population genetics, and evolutionary biology could inform and improve the material covered at medical schools. These learning objectives and training activities all address core competencies, and would reach the most students if woven seamlessly throughout the preclinical and clinical medical curriculum. There is also a need for anthropologists, sociologists, human population geneticists, and historians of race to work closely with medical educators and practicing physicians to teach medical students and healthcare professionals how to incorporate knowledge about race, human genetic variation, and the determinants of health into clinical practice. While it will take time and effort to integrate anthropological, genetic, and evolutionary perspectives into the core medical curriculum and clinical practice, it will improve diagnosis and treatment plans for diverse patient populations and help advance changes at the community, institutional, and policy levels that are necessary to reduce racial/ethnic health disparities and promote the health of all patients.

\section{ACKNOWLEDGEMENTS}

I would like to thank Abigail Bigham and Amy Non for organizing the 2015 American Association of Anthropological Genetics (AAAG) symposium on "Rethinking Racial Health Disparities: the Genetic Anthropologist's Contribution to Debates Over Health Inequalities", which inspired this special issue. I thank Lundy Braun, Theodore Held, John Hoberman, Austin Reynolds, Rick Smith, and two anonymous reviewers for helpful comments on an earlier version of this manuscript. I am also grateful to the many people who contributed to the working groups at the University of Texas at Austin in 2013 and 2014, including Daniel Bolnick, Vence Bonham, Richard Garcia, Paul Godley, Ernesto Gonzalez, Clarence 
Gravlee, Helena Hansen, John Hartigan, Theodore Held, John Hoberman, Seth Holmes, Joyce James, Jonathan Kahn, Jay Kaufman, Miyong Kim, Diane Magrane, Jamie McGuire, Jonathan Metzl, Michael Montoya, Stephen Pont, Rayna Rapp, Dorothy Roberts, Charles Rotimi, Melissa Smith, Karen-Sue Taussig, and Shetal Vohra-Gupta. Funding and support for the working groups came from the College of Liberal Arts, University Health Services, and Dell Medical School at the University of Texas at Austin, as well as from the Seton Healthcare Family.

Received 24 December 2015; accepted 13 May 2016. 


\section{Literature Cited}

Alcock, J., and M. D. Schwartz. 2011. A clinical perspective in evolutionary medicine: what we wish we had learned in medical school. Evo. Edu. Outreach 4:574-579.

Awosogba, T., J. R. Betancourt, F. G. Conyers et al. 2013. Prioritizing health disparities in medical education to improve care. Ann. N. Y. Acad. Sci. 1287:17-30.

Ayanian, J.Z., P. D. Cleary, J. H. Keogh et al. 2004. Physicians' beliefs about racial differences in referral for renal transplantation. Am. J. Kidney Dis. 43:350357.

Baer, R.D., E. Arteaga, K. Dyer et al. 2013. Concepts of race and ethnicity among health researchers: patterns and implications. Ethn. Health 18:211-225.

Barbujani, G., S. Ghirotto, and F. Tassi. 2013. Nine things to remember about human genome diversity. Tissue Antigens 82:155-164.

Betancourt, J. R. 2006. Eliminating racial and ethnic disparities in health care: what is the role of academic medicine? Acad. Med. 81:788-792.

Bolnick, D. I., N. Steinel, A. W. Reynolds, and D. A. Bolnick. In review. Learning objectives for weaving evolutionary thinking into medical education. $A d v$. Health Sci. Educ.

Bonham, V. L., S. L. Sellers, and S. Woolford. 2014. Physicians' knowledge, use, and beliefs about race and genetic variation: new measures and new insight. BMC Health Serv. Res. 14:456.

Braun, L., A. Fausto-Sterling, D. Fullwiley et al. 2007. Racial categories in medical practice: how useful are they? PLoS Medicine 4(9):1423-1428.

Braveman, P., S. Egerter, and D. R. Williams. 2011. The social determinants of health: coming of age. Annu. Rev. Public Health 32:381-398.

Brooks, K. C. 2015. A silent curriculum. JAMA 313:1909-1910.

Carpenter-Song, E. A., S. M. Nordquest, and J. Longhofer. 2007. Cultural competence reexamined: critique and directions. Psychiatr. Serv. 58:136265 .

Centers for Population Health and Health Disparities. 2007. Cells to Societies: Overcoming Health Disparities. Bethesda: National Institutes of Health.

Centers for Disease Control and Prevention. 2011. CDC Health Disparities and Inequalities Report - United States, 2011. CDC Morbidity and Mortality Weekly Report, Supplement Vol. 60. Atlanta: Centers for Disease Control and Prevention.

Cooper, R. S., K. Wolf-Maier, A. Luke et al. 2005. An international comparative study of blood pressure in populations of European vs. African descent. BMC Med. 3:2.

Coria, A., T. G. McKelvey, P. Charlton et al. 2013. The design of a medical 
school social justice curriculum. Acad. Med. 88:1442-1449.

Fofana, M. O. 2013. The spectre of race in American medicine. Med. Humanit. 39:137-141.

Frodi, T., E. Reinhold, N. Koutsouleris et al. 2010. Childhood stress, serotonin transporter gene and brain structures in major depression. Neuropsychopharmacology 35:1383-1390.

Garcia, R. 2003. The misuse of race in medical diagnosis. Pediatrics 113:13941395.

Gire, S. K., A. Goba, K. G. Andersen et al. 2014. Genomic surveillance elucidates

Ebola virus origin and transmission during the 2014 outbreak. Science 345:1369-1372.

Gluckman, P., A. Beedle, and M. Hanson. 2009. Principles of Evolutionary Medicine. New York: Oxford University Press.

Gluckman, P. A., and C. T. Bergstrom. 2011. Evolutionary biology within medicine: a perspective of growing value. BMJ 343:d7671.

Goldstein, D., and J. Holmes. 2011. Physicians' daily life report. rwjf.org/content/dam/web-assets/2011/11/2011-physicians--daily-lifereport

Gravlee, C. C. 2009. How race becomes biology: embodiment of social inequality. Am. J. Phys. Anthropol. 139:47-57.

Green, A. 2015. Task force aims to rid med school courses of racial bias. The Brown Daily Herald, December 3.

Hill, M. A. 1997. The curse of frybread: the diabetes epidemic in Indian country. Winds of Change 12:26-31.

Hoberman, J. 2012. Black and Blue: The Origins and Consequences of Medical Racism. Berkeley: University of California Press.

Hoffman, K. M., S. Trawalter, J. R. Axt, and M. N. Oliver. 2016. Racial bias in pain assessment and treatment recommendations, and false beliefs about biological differences between blacks and whites. Proc. Nat. Acad. Sci. U.S.A. 113:4296-4301.

Hunt, L. M., N. D. Truesdell, and M. J. Kreiner. 2013. Genes, race, and culture in clinical care: racial profiling in the management of clinical care. Med. Anthropol. Q. 27:253-271.

Johnson, T. J., M. D. Weaver, S. Borrero et al. 2013. Association of race and ethnicity with management of abdominal pain in the emergency department. Pediatrics 132:e851-e858.

Johnstone, S. E., and S. B. Baylin. 2010. Stress and the epigenetic landscape: a link to the pathobiology of human diseases? Nat. Rev. Genet. 11:806-812.

Joyce B. 2006. An introduction to competency based residency education. Accreditation Council for Graduate Medical Education, Chicago, IL. 
Kaufman, J. S., L. Dolman, D. Rushani, and R. S. Cooper. 2015. The contribution of genomic research to explaining racial disparities in cardiovascular disease: a systematic review. Am. J. Epidemiol. 181:464-472.

Kumagai, A. K., M. L. Lypson. 2009. Beyond cultural competence: critical consciousness, social justice, and multicultural education. Acad. Med. 84:782-787.

Malik, V. S., W. C. Willett, and F. B. Hu. 2013. Global obesity: trends, risk factors and policy implications. Nat. Rev. Endocrinology 9:13-27.

McClung, C. A., and E. J. Nestler. 2008. Neuroplasticity mediated by altered gene expression. Neuropsychopharmacology 33:3-17.

Metzl, J. M. 2009. The Protest Psychosis: How Schizophrenia Became a Black Disease. Beacon Press.

Metzl, J. M., and H. H. Hansen. 2014. Structural competency: theorizing a new medical engagement with stigma and inequality. Soc. Sci. Med. 103:126133.

Metzl, J. M., and D. E. Roberts 2014. Structural competency meets structural racism: race, politics, and the structure of medical knowledge. American Medical Association Journal of Ethics 16:674-690.

Nesse, R. M., C. T. Bergstrom, P. T. Ellison et al. 2010. Making evolutionary biology a basic science for medicine. Proc. Nat. Acad. Sci. U.S.A. 107:1800-1807.

Nesse, R. M, and J. D. Schiffman. 2003. Evolutionary biology in the medical school curriculum. Bioscience 53:585-587.

Omenn, G. S. 2010. Evolution and public health. Proc. Nat. Acad. Sci. U.S.A. 107:1702-1709.

Ossorio, P., and T. Duster. 2005. Race and genetics: controversies in biomedical, behavioral, and forensic sciences. Am. Psychol. 60:115-128.

Pearlman, R. 2013. Evolution and Medicine. New York: Oxford University Press.

Robert Wood Johnson Foundation. 2011. Health Care's Blind Side: The Overlooked Connection between Social Needs and Good Health. Princeton: Robert Wood Johnson Foundation.

Sankar, P., M. K. Cho, C. M. Condit et al. 2004. Genetic research and health disparities. JAMA 291:2985-2989.

Shields, A. E., M. Fortun, E. M. Hammonds et al. 2005. The use of race variables in genetic studies of complex traits and the goal of reducing health disparities. Am. Psychol. 60:77-103.

Smedley, B. D., A. Y. Stith, and A. Nelson, eds. 2003. Unequal Treatment: Confronting Racial and Ethnic Disparities in Health Care. Washington, DC: National Academies Press. 
Smith, W. R., J. R. Betancourt, M. K. Wynia et al. 2007. Recommendations for teaching about racial and ethnic disparities in health and health care. Ann. Intern. Med. 147:654-665.

Sullivan, S. 2013. Inheriting racist disparities in health: epigenetics and the transgenerational effects of white racism. Critical Philosophy of Race $1: 190-218$.

Stearns, S. C. 2011. On designing courses in evolutionary medicine. Evo. Edu. Outreach 4:589-594.

Stearns, S. C. 2012. Evolutionary medicine: its scope, interest and potential. Proc. Biol. Sci. 279:4305-4321.

Tammen, S. A., S. Friso, and S.-W. Choi. 2013. Epigenetics: the link between nature and nurture. Mol. Aspects Med. 34:753-764.

Tang E. 2012. Austin has taken a great leap backward in racial equality. Austin American-Statesman. June 18.

Taylor, S. L., A. Fremont, A. K. Jain et al. 2006. Racial and ethnic disparities in care: the perspectives of cardiovascular surgeons. Ann. Thorac. Surg. 81:531-536.

Thayer, Z. M., and C. W. Kuzawa. 2011. Biological memories of past environments: epigenetic pathways to health disparities. Epigenetics 6:798803.

Thayer, Z. M., and A. L. Non. 2015. Anthropology meets epigenetics: current and future directions. Am. Anthropol. doi:10.1111/aman.12351

The Joint Commission. 2010. Advancing Effective Communication, Cultural Competence, and Patient- and Family-Centered Care: A Roadmap for Hospitals. Oakbrook Terrace, IL: The Joint Commission.

The SIGMA Type 2 Diabetes Consortium. 2014. Sequence variants in SLC16A11 are a common risk factor for type 2 diabetes in Mexico. Nature 506:97-101.

Todd, K. H., C. Deaton, A. P. D'Adamo, and L. Goe. 2000. Ethnicity and analgesic practice. Ann. Emerg. Med. 35:11-16.

Todd, K. H., N. Samaroo, and J. R. Hoffman. 1993. Ethnicity as a risk factor for inadequate emergency department analgesia. JAMA 269:1537-1539.

Trevathan, W. R., E. O. Smith, and J. J. McKenna, eds. 2008. Evolutionary Medicine and Health: New Perspectives. New York: Oxford University Press.

Tuckson, R. V., L. Newcomer, and J. De Sa. 2013. Accessing genomic medicine: affordability, diffusion, and disparities. JAMA 309:1469-1470.

U.S. Department of Health and Human Services. 2011. HHS Action Plan to Reduce Racial and Ethnic Health Disparities. Washington, DC: U.S. Department of Health and Human Services. 
Werner, R. M., D. A. Asch, and D. Polsky. 2005. Racial profiling: the unintended consequences of coronary artery bypass graft report cards. Circulation 111:1257-1263.

Williams, P. D. 2009. Darwinian interventions: taming pathogens through evolutionary ecology. Trends in Parasitology 26:83-92.

Williams, D. R., and R. Wyatt. 2015. Racial bias in health care and health: challenges and opportunities. JAMA 314:555-556.

Witzig, R. 1996. The medicalization of race: scientific legitimization of flawed social construction. Ann. Int. Med. 125:675-679.

Yusuf S., and S. Anand. 2010. Deciphering the causes of cardiovascular and other complex diseases in populations: achievements, challenges, opportunities, and approaches. Prog. Cardiovasc. Dis. 53:62-67. 


\section{Table 1. Examples of Racial/Ethnic Health Disparities in the United States. ${ }^{1}$}

Female life expectancy (years), 2011:

White: $83 \quad$ Black: 77

Male life expectancy (years), 2011:

White: $78 \quad$ Black: 70

Infant mortality death rate (per 1,000), 2006:

White: $5.6 \quad$ Black: $13.3 \quad$ Hispanic: 5.41

Death rate (per 100,000) for coronary heart disease, 2006:

White: $134.2 \quad$ Black: $161.6 \quad$ Hispanic: 106.4

Death rate (per 100,000) for stroke, 2006:

White: $41.7 \quad$ Black: 61.6 Hispanic: 34.2

Prevalence (\%) of hypertension, 2008:

White: 28.8 Black: $42 \quad$ Hispanic: 25.5

Pre-term birth rate (\%), 2007:

White: $11.5 \quad$ Black: $18.3 \quad$ Hispanic: 12.3

Prevalence (\%) of asthma, 2008:

White: $7.8 \quad$ Black: $9.5 \quad$ Hispanic: 14.2

Prevalence (\%) of diabetes, 2008:

White: 7 Black: $11 \quad$ Hispanic: 10.7

Breast cancer incidence \& deaths (per 100,000), 2012 :

Incidence:

White: $127.9 \quad$ Black: $124.4 \quad$ Hispanic: 92.1

Deaths:

White: $21.3 \quad$ Black: $30.2 \quad$ Hispanic: 14.5

Prostate cancer incidence \& deaths (per 100,000), 2012:

Incidence:

White: $130.4 \quad$ Black: $214.5 \quad$ Hispanic: 114.7

Deaths:

White: 19.8

Black: $46.3 \quad$ Hispanic: 17.8

${ }^{1}$ CDC Health Disparities \& Inequalities Report - U.S., 2011; National Cancer Institute SEER Cancer Statistics Review, 2015 
Table 2. Examples of Racial/Ethnic Profiling and Unequal Treatment in the Clinic.

Inequities in pain management and length of stay in hospital emergency rooms: $55 \%$ of Hispanics and $43 \%$ of blacks vs. $26 \%$ of whites receive no pain medication for long-bone fractures, despite similar pain reports $\&$ adjusting for confounders. (Todd et al. 1993; Todd et al. 2000)

Black and Hispanic children admitted to the ER with severe abdominal pain are significantly less likely to receive any analgesic than white children, and they experience a prolonged length of stay as a result. (Johnson et al. 2013)

Racial profiling and inequities in psychiatric diagnosis:

Black patients have been consistently over-diagnosed with schizophrenia but under-diagnosed with anxiety disorders and depression. (Metzl 2009)

Inequities in access to organ transplantation:

Black patients are less likely to get kidney transplantations than white patients. When physicians improperly doubt the value of kidney transplantation to black patients, or misunderstand black patient preferences, they risk the lives of black patients who want transplants. (Ayanian et al. 2004)

Inequities in diagnostic/therapeutic cardiovascular care:

A large proportion of cardiovascular surgeons reported that black patients are less likely than white patients to receive cardiac tests/procedures and therapeutic tests/procedures.

(Taylor et al. 2006)

Racial profiling and inequities associated with coronary artery bypass graft report cards:

When physicians believe that minorities are at higher risk for poor outcomes, despite insufficient evidence, minority patients are denied this procedure more often than white patients. (Werner et al. 2005)

Racial profiling in diagnosis of sickle-cell anemia:

Assumptions about a patient's race affect what disease diagnoses are considered, leading to potentially serious negative consequences. Two case reports illustrate this occurrence:

Case 1: "An 8-year-old boy, phenotypically European, presented with acute abdominal pain and anemia (hematocrit, 0.21). Although his body temperature 
was only $37.9^{\circ} \mathrm{C}$, surgery was considered. A technician found red corpuscles with hemolytic characteristics on a smear. Surgery was canceled after the results of a subsequent sickle preparation were found to be positive, and the child was treated for previously undiagnosed sickle cell anemia. His parents were from Grenada and were of Indian, northern European, and Mediterranean ancestry."

Case 2: "A 24-year-old man, who was classified as black during the medical history, presented with progressive upper abdominal pain for 24 hours and was found to have a hematocrit of 0.22 . He stated that a doctor once told him he had "sickle cell," but he had never been hospitalized and had never needed treatment. The patient was admitted for management of sickle cell crisis, and two packed red blood cell units were transfused during the ensuing 24 hours. The next morning, the patient had a witnessed cardiac arrest and was intubated immediately. During intubation, bright red blood was suctioned out of the pharynx and esophagus but oxygenation remained excellent. The patient could not be resuscitated despite a 75-minute advanced cardiac life support effort. His hematocrit at the time of the code was 0.13 , and he had exsanguinated from a bleeding peptic ulcer."

(Witzig 1996:677) 


\section{Table 3. Examples of Recommended Learning Objectives.}

Identify the key social, structural, and institutional determinants of health (e.g., socioeconomic status, race, gender, culture, environment, policies), and explain how racism, poverty, gender inequality, inadequate education, and other social and environmental stressors contribute to poor health and disease.

Define and differentiate between race, ethnicity, and genetic ancestry.

Recognize that most racial and ethnic health disparities are not due to genetic differences between the racial groups recognized in the United States.

Explain why perceived or self-identified race or ethnicity should not be used as a proxy for genotype, disease phenotype, or genetic ancestry.

Describe examples of clinical best practices that can facilitate the elimination of racial/ethnic biases in patient care or help reduce health disparities.

Explain how to apply the principles of evidence-based medicine in clinical practice, with diagnosis and treatment decisions based on scientific evidence rather than racial/ethnic stereotypes.

Make recommendations for potential research, clinical practice guidelines, and policies to alleviate health disparities along racial, gendered, economic class, cultural, and environmental lines.

Describe how past and contemporary evolution has led to genetic variation within and among human populations, including the role of mutation, genetic drift, and natural selection in generating genetic variation and disease.

Explain how human evolutionary history can help physicians more accurately diagnose disorders and plan appropriate treatment.

Apply the application of analytical tools from evolutionary biology and anthropological genetics (e.g. genetic ancestry testing, phylogenetics, association mapping, genomic signatures of selection) to identify patient and pathogen ancestry.

Explain how patient and pathogen ancestry information may be used to identify sources of infection, evaluate patient risk of genetic disease, and map the genetic basis of phenotypes. 